\title{
LEARNING FROM ERRORS -TOPIRAMATE INDUCED BILATERAL ANGLE CLOSURE WITH ACUTE ONSET MYOPIA
}

Nayana Prabhu1, Sarita Gonsalves², Vishnu Prabhu³ ${ }^{3}$ Pratima B. Patil ${ }^{4}$

\section{HOW TO CITE THIS ARTICLE:}

Nayana Prabhu, Sarita Gonsalves, Vishnu Prabhu, Pratima B. Patil. "Learning from Errors -Topiramate Induced Bilateral Angle Closure with Acute Onset Myopia". Journal of Evolution of Medical and Dental Sciences 2014; Vol. 3, Issue 68, December 08; Page: 14723-14727, DOI: 10.14260/jemds/2014/3978

ABSTRACT: Topiramate is an oral sulfamate medication used primarily for seizure treatment and has also demonstrated efficacy in the treatment of bipolar disorders and migraine.

The mechanism of causation of angle closure and acute myopia is not clearly understood and several theories have been proposed of which the uveal effusion theory is widely accepted. We report a case of topiramate induced acute myopia with bilateral acute angle closure.

With the increase in the frequency of prescribing topiramate for migraine prophylaxis it is important that the prescribing physicians should be aware of these complications. It is also important to educate the patients regarding the possible symptoms so that they can report at the earliest.

INTRODUCTION: Several drugs are known to cause angle closure and induce acute myopic shift in refraction. The mechanism of causation is not clearly understood and several theories have been proposed. Topiramate is a new antiepileptic drug which is used in several medical conditions like migraine, epilepsy, de addiction. We report a case of topiramate induced acute myopia, with acute angle closure which was wrongly diagnosed.

A 39 year old male presented with history of sudden onset headache with nausea and vomiting of 2 days duration. He was using spectacles of $-1.00 \mathrm{DS} /-1 \mathrm{DC} \times 90^{\circ}$ in the right eye and$1.25 \mathrm{DS} /-1.00 \mathrm{DC} \times 90^{\circ}$ in the left eye of for the past 20years. He was a known alcoholic was under the care of psychiatrist and had undergone de addiction 10 years ago. 10 days ago he had a relapse and presented with disulphiram like reaction after a binge of alcohol. He was admitted and then was discharged on tab topiramate $25 \mathrm{mg}$ - for 3 days followed by $50 \mathrm{mg}$ for 10 days. 5 days after initiating treatment he presented with sudden onset headache with nausea and vomiting.

On examination he was restless but oriented, his vitals were stable. He was clinically diagnosed to have a cerebro vascular accident and was admitted in the intensive care unit. A whole battery of investigations was ordered including CT brain which was all normal. Finally the ophthalmologist was called in owing to bilateral congestion and chemosis in the eyes (Fig-1). On examination he had 45degrees of exotropia, his visual acuity in both the eyes was $2 / 200$ improving with pinhole to $20 / 20$, near vision $\mathrm{N}_{6}$. Refraction was -8.00 DS/ $2.75 \mathrm{DC} \times 90^{\circ}$ in the right eye and 8.00DS/-2.00DC $\times 90^{\circ}$ in the left eye. AC was shallow (Fig-2) and pupils were $4 \mathrm{~mm}$ sluggishly reacting to light. IOP measured by applanation was 40 and $42 \mathrm{mmHg}$ in the right and left eye respectively. Gonioscopy showed 360 degrees oppositional angle closure in both eyes (Fig-3). Examination of fundus showed the presence of fine retinal striae radiating from the fovea and no peripheral choroidal detachment. A diagnosis of topiramate induced acute bilateral angle closure with bilateral acute myopia was made and the drug was discontinued immediately in consultation with the psychiatrist. When reviewed 24 hours after the discontinuation of medication, his BCVA was 20/60 with previous acceptance. AC was still shallow and IOP measured by applanation was $37 \mathrm{~mm}$ of $\mathrm{Hg}$ in 
both eyes. On day 4 IOP was $23 \mathrm{mmhg}$ in the right eye and $18 \mathrm{~mm}$ hg in the left eye. Fundus examination was within normal limits with the disappearance of retinal striae.

Patient was discharged on topical 0.5\%Timolol malleate and on review 1 week later his visual acuity was 20/20 in both eyes with previous correction. AC was of normal depth. (Fig-4).The intra ocular pressure was $7 \mathrm{mmHg}$ in the right eye and $10 \mathrm{mmHg}$ in the left eye. (Fig-5).

DISCUSSION: Topiramate is an oral sulfamate medication used primarily for seizure treatment that also demonstrates efficacy in the treatment of bipolar disorders, alcohol de addiction and in the control of migraine.

The exact mechanism by which Topiramate induces angle closure and myopia is not clearly understood. Swelling of the crystalline lens due to the alterations in the sodium and chloride movement caused by weak carbonic anhydrase inhibitor activity of topiramate has been postulated. ${ }^{1}$ Prostaglandin mediated ciliary body swelling causing forward movement of the crystalline lens has been documented using ultrasound biomicroscopy. ${ }^{2}$ Second theory is more widely accepted. Similar case of acute myopia in the absence of angle closure has been reported. ${ }^{3}$

These cases are likely to be misdiagnosed as stroke based on clinical symptoms without ophthalmic examination leading to unnecessary wastage of resources to the hospital and finances to the patient. Whenever a patient presents with acute headache and vomiting ophthalmic examination is a must and whenever a case of bilateral acute angle-closure glaucoma associated with myopia and a shallow anterior chamber is encountered, ciliochoroidal effusion syndrome induced by drugs should be considered in the differential diagnosis. As the mechanism of angle closure does not involve pupillary block peripheral iridotomy is ineffective in these cases. ${ }^{2}$

The majority of reported adverse events have occurred in female patients (up to 89\%) with a mean age of 36.5 yaers. ${ }^{4}$ But our patient was a middle aged male which makes this case report unique.

\section{CONCLUSIONS:}

- With the increase in the frequency of prescribing topiramate for migraine prophylaxis and de addiction it is important that ophthalmologists and physicians should be aware of these complications.

- Stopping the medication is the mainstay of treatment.

- Two signs: help in clinically distinguishing from acute angle closure glaucoma.

- Ciliary congestion, which was remarkably less.

- The presence of reactive, though sluggish, pupil, contrary to the Fixed dilated pupil as seen in AACG.

- It is also important to educate the patients regarding the possible symptoms so that patients can report at the earliest.

\section{REFERENCES:}

1. Harsh S, O'Halloran, Lee W B. Topiramate induced acute myopia and retinal striae Arch Ophthalmol. 2001; 119: 775-777.

2. Rhee DJ, Goldberg MJ, Parrish RK. Bilateral angle-closure glaucoma and ciliary body swelling from topiramate. Arch Ophthalmol 2001; 119:1721-3. 


\section{CASE REPORT}

3. Mahesh G, Giridhar A, Saikumar SJ, Sachin Fegdex Drug-induced acute myopia following chlorthalidone treatment ijo 2007 55:386-388.

4. Bhattacharya B K, Basu S Acute myopia induced by topiramate: Report of a case and review of the literature Neurology 2005; 53; 108-109.

Fig. 1: Showing bilateral lid edema, chemois and features of angle closure.

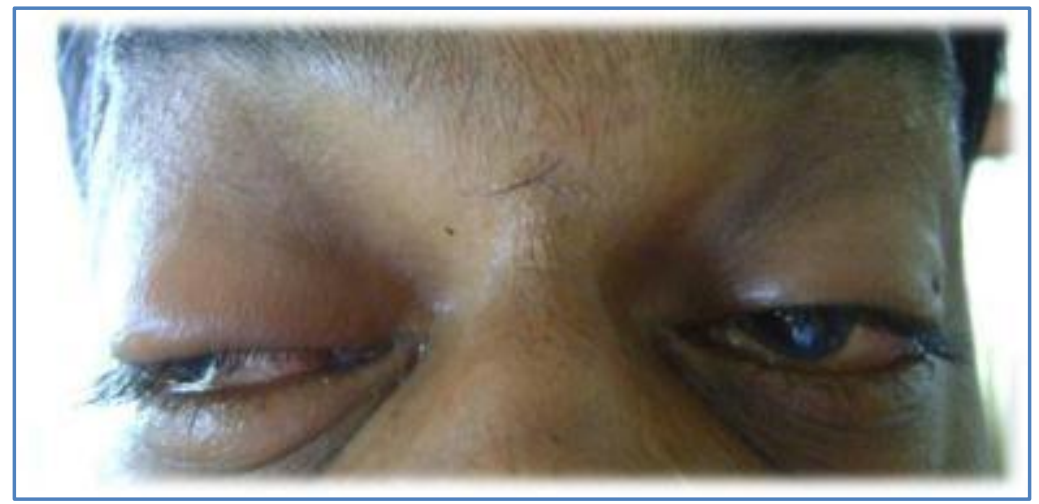

Fig. 1

Fig. 2: Slit lamp examination showing shallow anterior chamber.

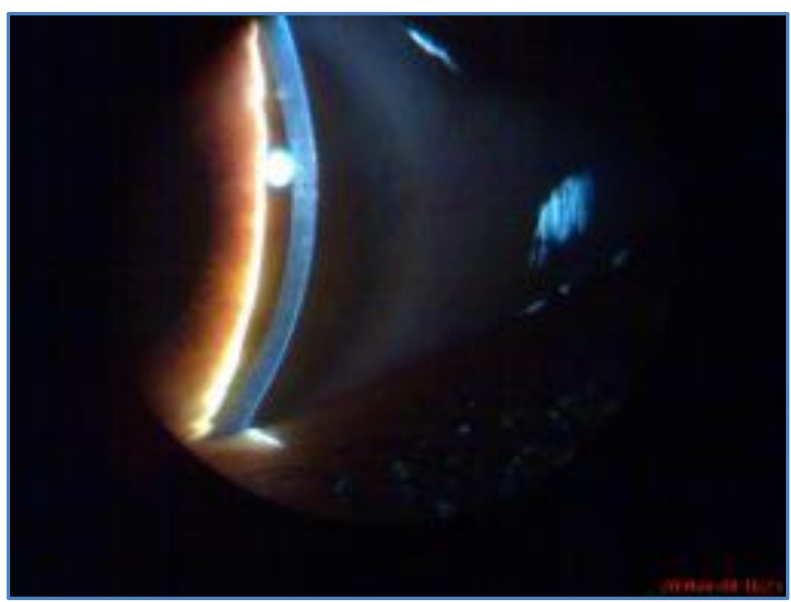

Fig. 2 


\section{CASE REPORT}

Fig. 3: Gonioscopy showing oppositional angle closure.

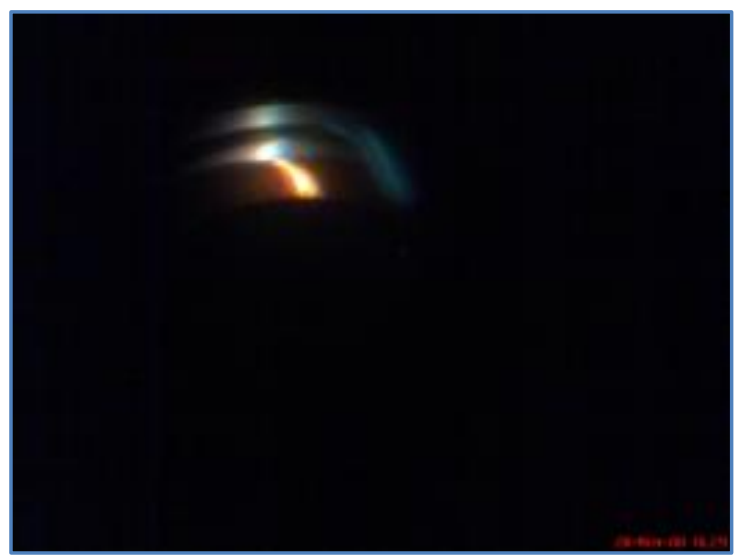

\section{Fig. 3}

Fig. 4: Slit lamp examination post treatment showing improvement in the anterior chamber angle depth.

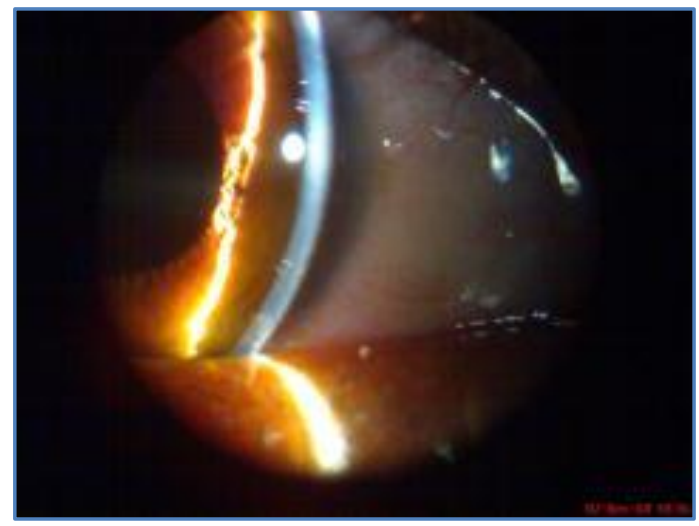

\section{Fig. 4}

Fig. 5: Resolution of angle closure and myopia following treatment.

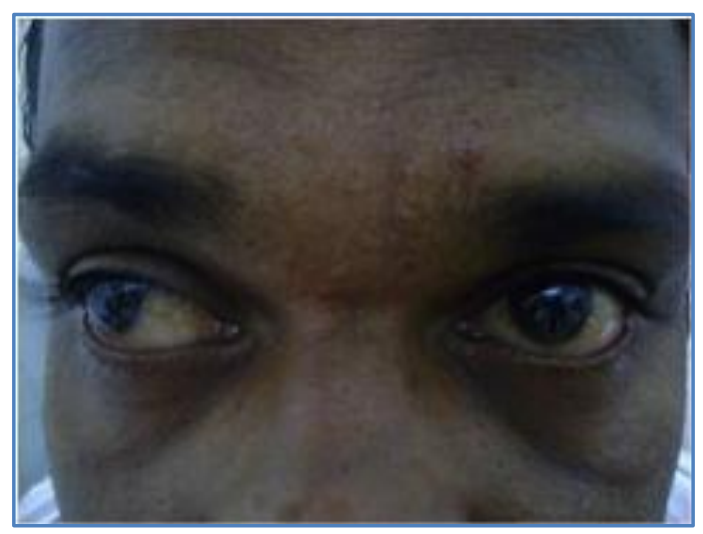

Fig. 5 


\section{AUTHORS:}

1. Nayana Prabhu

2. Sarita Gonsalves

3. Vishnu Prabhu

4. Pratima B. Patil

\section{PARTICULARS OF CONTRIBUTORS:}

1. Associate Professor, Department of Obstetrics and Gynaecology, Srinivas Medical College, Mangalore.

2. Assistant Professor, Department of Ophthalmology, Srinivas Medical College, Mangalore.

3. Professor and HOD, Department of Ophthalmology, Srinivas Medical College, Mangalore.
4. Assistant Professor, Department of Anaesthesia, M. R. Medical College, Gulbarga.

\section{NAME ADDRESS EMAIL ID OF THE CORRESPONDING AUTHOR:}

Dr. Nayana Prabhu,

Associate Professor,

Department of Obstetrics and Gynaecology, Srinivas Medical College, Mangalore.

Email: nayana.nethralaya@gmail.com

Date of Submission: 20/11/2014.

Date of Peer Review: 21/11/2014.

Date of Acceptance: 02/12/2014.

Date of Publishing: 08/12/2014. 